\title{
¿De qué hablamos cuando hablamos de medicalización? Sobre adjetivaciones, reduccionismos y falacias del concepto en ciencias sociales
}

What are we talking about when we talk about medicalization? On adjectivally uses, reductionisms and fallacies on the concept in social sciences

Eugenia Bianchi

Docente de la FSoc (UBA)-Investigadora en Instituto de Investigaciones Gino Germani(IIGG). Grupo de Estudios sobre Salud Mental y Derechos Humanos (GESMyDH), Argentina

eugenia.bianchi@gmail.com

\section{Resumen:}

En ciencias sociales, el concepto de medicalización está presente como asunto de agenda cultural, social, económica y políticolegislativa, y es convocante en espacios académicos, investigativos y clínico-profesionales. Simultáneamente, en estos espacios se evidencian inexactitudes ligadas al concepto y su circulación, que suponen limitaciones y fragilidad argumentativa. Sintetizo las inexactitudes en tres líneas: adjetivación, reducción e impropiedad, cuyos límites entre sí son más analíticos que empíricos. El objetivo de este escrito es presentar algunas implicancias o corolarios teórico-metodológicos que se derivan de estas inexactitudes, empleando métodos analítico-interpretativos sobre bibliografía específica, nacional e internacional, y con el ejemplo empírico del TDAH.

Palabras clave: Medicalización, Concepto, Metodología, TDAH (trastorno por déficit de atención e hiperactividad).

\section{AbStract:}

Within the field of social sciences, medicalization as a concept is a regular matter of cultural social, economic and politicallegislative agenda. It is also convening in academicals, research, clinical and professional spaces, in which some inaccuracies related to the concept and its circulation, became evident. These inaccuracies can be resumed in three lines: the adjectivally use of the concept, the reduction of the concept and the inappropriateness of the concept. This paper's objective is to present some theoretical and methodological implications and corollaries which are derived from the inaccuracies mentioned above. In order to do so, some analytical and interpretative methods on specific national and international bibliography are used, with ADHD as an empirical example.

KeYwords: Medicalization, Concept, Methodology, ADHD (attention deficit hyperactivity disorder). 


\section{INTRODUCCIÓN}

En la actualidad, el concepto de medicalización hace gala de inusitada y persistente pregnancia. Se trata de una característica poco habitual en las nociones provenientes del pensamiento social, ya que ha rebalsado los diques de contención de la academia y de la terminología sociológica específica, para ampliarse tanto a otras disciplinas científicas como a la cultura más general, los medios de comunicación y las noticias (Conrad, 2015). Refiriéndose en especial a la sociología médica, Davis (2009) ubica a la medicalización como uno de los conceptos de mayor éxito e importancia de esa corriente dentro del pensamiento social. Y según resaltan Bell y Figert (2015) no son muchos los ejemplos que comparten esta característica expansiva de la medicalización. De acuerdo con las autoras, el concepto apenas hace serie con otras nociones en las que se verifica este éxito y diseminación: la burocracia de Weber, el estigma social de Durkheim y Goffman, y el capital cultural de Bourdieu.

Busfield (2017) resume en dos a los motivos fundamentales por los que el concepto de medicalización todavía constituye una herramienta conceptual de alto valor para el análisis sociológico de la medicina, la salud y la enfermedad. En primer lugar, porque los procesos que este concepto permitió identificar, y que -podríamos añadir- se hicieron visibles como problemas sociológicos en virtud de esta categoría, siguen produciéndose en la actualidad. Es muy difícil disentir con Busfield cuando sostiene que la medicalización irrumpió vertiginosamente y continúa transformando la comprensión del comportamiento humano cotidiano, sus experiencias y problemas.

El segundo motivo por el que la medicalización es una herramienta conceptual clave, según Busfield, es porque pone de relieve las causas sociales que apuntalan la extensión de la medicina, y su impacto en el mundo social. Estas causas suponen un amplio rango de actores sociales y dimensiones económico-políticas.

A partir de esta argumentación, el objetivo de este artículo es presentar algunas implicancias teóricometodológicas que se derivan de estas inexactitudes. Para ello se emplean métodos analítico-interpretativos sobre bibliografía específica, nacional e internacional. La hipótesis sobre la que se sustenta el artículo postula que, al extender su influencia, la medicalización ha resignado matices y potencia analítica. Como corolario de esta hipótesis se sostiene que, en términos generales, las inexactitudes redundan en que las discusiones y las críticas alrededor del propio concepto exhiben una tendencia a volverse rigidificadas y estereotipadas, y que los términos en los que este circula, y los debates que se delinean en torno a él, omiten, obturan o impiden el planteamiento de otros términos para discutir y profundizar dentro del amplio campo problemático, temático y teórico-metodológico que la perspectiva está en condiciones de abordar.

Estas limitaciones y pérdida de fuerza argumental se pueden sintetizar en tres líneas, cuyos límites entre sí son más analíticos que empíricos. La primera es la adjetivación, que consiste en concebir al concepto de medicalización como un atributo de un individuo. De acuerdo con esta descripción, la medicalización sería algo que caracteriza o le ocurre a alguien, frecuentemente de modo coercitivo y externo a sus intenciones o capacidad de manejarlo. La segunda consiste en la reducción de los múltiples aspectos del proceso a dos principales. Una de las reducciones ocurre cuando se considera que medicalización es sinónimo de prescripción de medicación, tomando el consumo de medicamentos como aspecto indispensable para que ocurra el proceso de medicalización. La otra reducción se da cuando se asume que la medicalización es un asunto de médicos, y que son estos profesionales los principales o excluyentes involucrados en el proceso.

La tercera limitación reside en asumir que los fenómenos asociados a la medicalización son de alguna manera impropios o falaces, y que por ello no les corresponde "verdaderamente" estar medicalizados.

Para desarrollar esta hipótesis, se revisan, analizan y presentan argumentaciones que contribuyan a comprender estas dos facetas del fenómeno -es decir, la gran llegada y la simultánea subutilización de las fortalezas teórico-metodológicas del concepto y la perspectiva-, a la vez que se marcan algunos límites que la misma tiene para ofrecer coordenadas de comprensión y análisis de ciertos procesos y dinámicas. Esto requiere 
seleccionar, sistematizar y exponer elementos de algunas producciones académicas, que resultan útiles en términos metodológicos y para la investigación de la medicalización desde las ciencias sociales.

Más ampliamente, estas hipótesis y objetivos se sustentan en reflexiones respecto de discusiones y agendas que rigen mayoritariamente la circulación de trabajos ligados a la perspectiva de la medicalización en América Latina. De ese panorama extraigo la convicción de que los fenómenos medicalizados, en general, son objetos de estudio caracterizables como complejos, en tensión y en curso.

El artículo se organiza en dos partes. La primera parte abarca las secciones 2, 3 y 4 . En la sección 2 se realiza la revisión de algunos autores, investigaciones, temas y nociones que aportaron al posicionamiento de la medicalización como una corriente de sostenida y creciente participación en el pensamiento social. En la sección 3 se exponen y analizan las contribuciones de nuevas corrientes, autores y conceptos que revitalizan la perspectiva en el siglo XXI. En la sección 4 se avanza en el análisis de algunos aspectos de la globalización de los diagnósticos medicalizados, con un enfoque especial en América Latina, y algunas particularidades del proceso.

En la segunda parte, que incluye las secciones 5, 6, 7 y 8 , se avanza sobre algunas de las limitaciones en la circulación del concepto de medicalización en Argentina y la región, y se describen y analizan algunas inexactitudes posibles. La sección 5 presenta las diferentes limitaciones que se analizan más detalladamente en las siguientes secciones, enfocando el análisis en los efectos que estas limitaciones traen para la investigación en ciencias sociales. En la sección 6 se caracteriza y analiza la adjetivación del concepto, en la sección 7 se analizan dos reduccionismos que circulan en torno al concepto, y en la sección 8 se trabaja acerca de los efectos de considerar que existen fenómenos propios de la medicalización, y otros que no lo son. Por último, en la sección 9 se recapitulan y cierran algunas líneas expuestas.

\section{Primera parte}

\section{2 ¿De dónde venimos? Los primeros exponentes del derrotero de la medicalización en el pensamiento social}

Desde la sociología, una referencia ineludible entre quienes impulsan los estudios de la medicalización es Conrad, quien en diferentes instancias de su camino investigativo viene sosteniendo que una de las claves de dicho concepto reside en su definición (Conrad, 1979, 1992, 2007, 2013). Un recorrido por los escritos de Conrad muestra que, como otros elementos de la perspectiva, la definición ha asumido diversos rasgos en los ya cincuenta años de producciones académicas.

Estas producciones se inician con el trabajo de Pitts (1968), discípulo de Parsons que acuñó el término en el marco de su análisis de la medicalización del comportamiento desviado. Pitts enfocó su análisis en cómo se controlan socialmente ciertos aspectos de la desviación, cuando pasan de concebirse como crímenes a entenderse como enfermedades. En esa línea, sostuvo que "la medicalización es uno de los medios de control social más efectivos (...) y está destinado a convertirse en el modo principal de control social formal" (Pitts, 1968, pp. 390-391).

Desde este escrito fundacional, la medicalización se diversificó notablemente, abrevando de diferentes escuelas y posturas teóricas en su medio siglo de existencia, una capacidad que le ha permitido pasar de ser una temática lateral en los estudios de la sociología médica en la década de 1970, a convertirse en un área pujante para el pensamiento social en el siglo XXI (Conrad, 2013; Busfield, 2017).

La variedad de campos y disciplinas que trabajan con esta perspectiva en la actualidad excede holgadamente a la sociología médica, para incidir también en otras disciplinas como la historia, la antropología, la salud pública, la economía y la bioética (Conrad, 2013), a los que se suman, más recientemente, los estudios sobre ciencia y tecnología (Sismondo, 2010) y sobre género (Riska, 2010). 
En 2013, Conrad publicó una suerte de "nuevo manifiesto" sobre la medicalización, revisando y actualizando algunos puntos centrales de la perspectiva y su concepto, y marcando algunas líneas a futuro de la misma. En ese trabajo se encargó de efectuar una reseña del conjunto de autores, escuelas y temas que fueron foco de interés en los años tempranos de la perspectiva de la medicalización. Su mapeo incluyó los estudios realizados desde la sociología de la desviación y el control social, la psiquiatría crítica y la antipsiquiatría, la historia y la filosofía críticas, la historia de la psiquiatría, la sociología estructural-funcionalista, el construccionismo, la teoría del etiquetamiento y el interaccionismo simbólico (Conrad, 2013). A la vez, estas escuelas y corrientes produjeron aportes que fueron cimentando la temática, y desarrollaron nociones conexas a la de medicalización que posicionaron la propuesta en el concierto de los estudios e investigaciones de las ciencias sociales.

Una sucinta revisión de estos aportes requiere detenerse en Parsons, quien en su análisis del sistema social subrayó la relevancia de la medicina en la diferenciación entre crimen y enfermedad, ambos considerados como formas de desviación, y analizó el rol social del enfermo. Parsons señaló además que la enfermedad no es un fenómeno exclusiva y simplemente natural, ya que en ella están implicadas "las interacciones motivadas de los seres humanos" (Parsons, [1951] 1999, p. 433), algo que hasta hoy fundamenta la pertinencia de las ciencias sociales para aproximarse a estas problemáticas.

En la década de 1970, Zola (1972) abordó a la medicina como una institución orientada al control social; y dejó planteadas algunas líneas de análisis que serían retomadas por otros autores con posterioridad. Entre ellas se destaca su apuesta por una perspectiva histórica para encarar los procesos, problemas, fenómenos y dinámicas medicalizadas, que prácticamente todos los autores que han realizado aportes a la corriente sostienen como principio teórico-metodológico. Otra línea que postula en su trabajo es la necesidad de tomar en cuenta otros dominios de saber junto con el médico, entre ellos la religión y la ley. Zola también llama la atención acerca del lugar de la medicina como sitio donde está depositada la verdad, y en el que los juicios y aseveraciones se realizan, presumiblemente, desde un lugar moralmente neutral y por expertos objetivos. Esta ligazón entre verdad, neutralidad y expertise también fue explorada por diversos autores en las décadas siguientes. Por último, ubicó el proceso por el cual la medicina expande las fronteras tanto de su ámbito de injerencia, como de las formas retóricas que se emplean como criterios argumentales en la vida cotidiana. Este aspecto es, para Zola, el más poderoso indicador de la medicalización de la sociedad.

Prácticamente para la misma época en la que fue publicado el artículo de Zola, en 1970, y desde la antipsiquiatría liberal, Szasz (2001) también había resaltado el rol de la psiquiatría como institución de control social, y había remarcado los vasos comunicantes entre la medicina, la religión y la moral. De hecho, en 1960 había acuñado la noción de mito de la enfermedad mental, con la que describió a la mayoría de las así denominadas enfermedades mentales como "problemas de la vida" (Szasz, 1973, p. 23). El trabajo de Szasz fue una temprana influencia para el pensamiento sociológico en torno a la medicalización de los comportamientos desviados, y ofreció el sustrato para que, en posteriores investigaciones, se abordasen problemáticas específicas de salud mental (Busfield, 2017)

Desde la Escuela de Sociología de Chicago también ampliaron la densidad analítica de la medicalización con diferentes nociones. Entre otros aportes, Goffman trabajó los conceptos de institución total, mortificación del yo, carrera moral y estigma (Goffman, 1998a, 1998b), que permiten incorporar matices analíticos para pensar los procesos de medicalización, a la vez que brindan herramientas y claves metodológicas valiosas para la inmersión en el campo.

Becker elaboró su teoría del etiquetamiento ejemplificando su definición con numerosas metáforas médicas. En particular señaló que la similitud entre enfermedades médicas y enfermedades mentales es sólo metafórica, porque ciertos comportamientos considerados socialmente desviados son asumidos como enfermedades mentales. Entre otros ejemplos, cita a la homosexualidad, el divorcio, el crimen, el arte, el liderazgo político indeseable y la participación en asuntos sociales. Para Becker, la metáfora médica reubica 
la fuente de la desviación en el individuo, y obtura la posibilidad de considerar que las imputaciones de desviación son parte del fenómeno a analizar (Becker, 2009).

La extensión de las metáforas médicas para pensar acerca de la desviación y el control social fue trabajada por Huertas $(2008,2009)$. En sus estudios historiográficos sobre el control social y la medicina, subrayó que los trabajos de Goffman y Foucault introdujeron aspectos críticos y discursivos que hasta entonces eran impensables, y que sus trabajos incorporaron elementos de análisis novedosos tanto para la historiografía como para la sociología tradicional. Y, en gran medida gracias a sus trabajos, la locura, el loco, y otras formas de enfermedad o desviación fueron analizados, ya no como venían siendo entendidos (es decir, como problemas sociales que entorpecen la integración social armónica) sino como construcciones de saberes que expresan una relación de poder, y que justifican la creación del espacio asilar en el que dicho poder se aplica.

Según Huertas, con este giro en el control social, el mismo comienza a ser entendido como un instrumento al servicio de la consolidación del poder de las clases dominantes, y deja de pensarse como un obstáculo para lograr la armonía social. Además, y como también marca Becker, la metáfora de la locura empezaría a ser usada en otros ámbitos y para hablar de otros sujetos históricos, que comparten con el loco el ser objeto de estrategias de coacción y poder en el corazón de la reproducción social (Huertas, 2008).

Por su parte, Freidson analizó el proceso de expansión de la institución médica, y avanzó sobre tópicos como los significados sociales de la enfermedad —en tanto puede considerarse como desviación social - y la autoridad profesional. Aunque no empleó ese lenguaje, Freidson también identificó el carácter performativo de los diagnósticos médicos, argumentando que, en tanto la medicina es “... la autoridad sobre lo que la enfermedad es «realmente» (...) crea las posibilidades sociales para representar la enfermedad” (Freidson, 1978, p. 209).

Desde una perspectiva marxista no ortodoxa, Illich (1976) articuló los conceptos de iatrogénesis clínica, social y estructural para analizar la medicalización de la vida. Además, trabajó la noción de imperialismo médico y abogó por una política de la salud que recuperara la autonomía personal y que, como resultado de la acción política, reforzara la dimensión ética de los tratamientos médicos. Illich describió el funcionamiento de la medicina y la iatrogenia que provoca, y cómo la extensión de la medicina absorbe cada vez más áreas de la vida cotidiana. También sostuvo que este proceso tiene una dimensión iatrogénica en sí, porque produce enfermedades y problemas que rompen tradiciones sociales de cuidado de la salud.

Finalmente, Foucault abordó la medicalización como estrategia de gobierno de los individuos y las poblaciones en los estados capitalistas (Foucault, 1996). En el esquema analítico de Foucault, el saber, el poder y las prácticas médicas y psiquiátricas tienen una participación central en la constitución de cuerpos y subjetividades (Foucault, 2004, 2005, 2002a, 2000), y un rol preponderante en los procesos de normalización social que se llevan adelante en las diferentes modalidades sociales en las que se ejerce el poder, sea que se trate de la disciplina o de la biopolítica (Bianchi, 2010). Asimismo, aportó herramientas conceptuales y metodológicas en su debate con Illich, entre ellas la noción de iatrogenia positiva.

Illich había avanzado en un análisis acerca de la capacidad de matar de la medicina, en función de su institucionalización, del monopolio profesional que ejerce en relación al cuidado de la salud, y del cientificismo. Illich desestima la supuesta eficacia de los médicos, mencionando una serie de ejemplos en los que queda expuesto que "el tratamiento específicamente médico de la gente nunca se relaciona en forma significativa con una disminución del complejo patológico ni con una elevación de la expectativa de vida"(Illich, 1976, p. 31).

Retomando los estudios de Illich, Foucault remarca que se tiene registro desde hace mucho tiempo de los efectos negativos de la medicina. Sin embargo, lo que sí es novedoso, a su juicio, es que hasta tiempos recientes, estos efectos negativos de la medicina, su capacidad de matar, eran entendidos como derivados de la ignorancia médica, de su falta de cientificidad. En sus palabras: 
La medicina mataba por la ignorancia del médico o porque la propia medicina era ignorante; no era una verdadera ciencia sino una rapsodia de conocimientos mal fundados, mal establecidos y verificados. La nocividad de la medicina se juzgaba en proporción a su no cientificidad (Foucault, 1996, p. 71).

Siempre siguiendo a Foucault, esto se modifica a partir del siglo XX, porque la peligrosidad de la medicina ya no reside solamente en su no-saber, en su ignorancia, falsedad o falta de cientificidad; sino en su saber mismo, y en la medida en que constituye una ciencia. Para Foucault, el peligro radica en el propio saber, y este saber es peligroso, no sólo por las consecuencias inmediatas en el individuo o grupo de individuos, sino para la propia historia, para la humanidad toda.

El análisis de la iatrogenia realizado por autores como Illich, dice Foucault, se fundamenta en las intoxicaciones y muertes por la administración de medicamentos, o intervenciones quirúrgicas innecesarias, pero para Foucault estos hechos se centran en la habilidad o ignorancia de los médicos, y no en cuestionar lo que para él es capital: la propia medicina y su cientificidad. Su propuesta, entonces, es atender no a la iatrogenia, sino a la iatrogenia positiva. Es decir, enfocarse no en los errores de diagnóstico o la ingesta accidental de sustancias, sino en los efectos médicamente nocivos derivados de la acción de la intervención médica en lo que esta tiene de fundamento racional (Foucault, 1996).

Para concluir esta sección, señalo un aspecto adicional que surge de la lectura de los trabajos mencionados: las múltiples y nutridas referencias cruzadas entre las obras de los autores, en cuanto al empleo de conceptos, ejemplos, procesos y dinámicas teóricas y metodológicas. Esta densa imbricación refuerza las argumentaciones acerca de la transversalidad e importancia de la medicalización como tema al interior de las diferentes corrientes del pensamiento social.

\section{3 ¿Dónde estamos y a dónde vamos? La medicalización en el siglo XXI. Nuevas corrientes, aportes y conceptos.}

De la revisión de los trabajos académicos de la sección anterior surge que los mismos estuvieron abocados mayoritariamente al estudio de la profesión médica, y de la medicina como institución, tópicos dotados de una significación destacada en ese entonces. Sin embargo, estudios realizados sobre las dinámicas más recientes del proceso muestran que los análisis relacionados con las facetas institucionales y profesionales de la medicina resultan insuficientes para dar cuenta de la creciente incidencia de otros actores y grupos como agentes activos, tanto de la medicalización como de la desmedicalización de los procesos vitales, sociales, legales y morales (Lupton, 1997; Bell y Figert, 2015; Conrad, 2005).

Para Lupton, las claves de aproximación elaboradas en lo que podríamos denominar el período temprano de la medicalización suponen un registro en trazos gruesos de la relación médico-paciente, que reducen la asimetría entre ambos a la mera opresión, dotan a la noción de medicalización de un carácter adjetivante peyorativo, y relegan otras dimensiones de análisis, como el alivio del dolor o la mejora de la salud (Lupton, 1997). De hecho, Bell y Figert marcan que la medicalización experimentó un giro, cuando las investigaciones comenzaron a exponer que la medicalización no era meramente "un proceso que se le hacía a la gente" (Bell y Figert, 2015, p. 22), sino que se configura como un proceso en el que las personas y grupos se pueden constituir en agentes activos que abogan, ya sea a favor o en contra de diagnósticos, o de la medicalización o desmedicalización de la vida.

Por su parte, Conrad y Schneider (1980) iniciaron un planteo sobre la medicalización que fue retomado y complejizado por Halfmann (2011) y reconsiderado por Clarke Mamo, Fosket, Fishman y Shim (2010) en su caracterización de la biomedicalización. Los autores ofrecieron una estructura de tres niveles concéntricos: conceptual, institucional u organizacional, y de interacción entre médico y paciente. En el primero, listan actores como gobiernos, organizaciones nacionales, y revistas e investigaciones médicas. En este nivel, el uso de un vocabulario o modelo médico apunta a la definición del problema, y no está centrado en los 
profesionales ni en los tratamientos. En el segundo, ubican actores pertenecientes a las organizaciones locales. El rol de los médicos es formal, se limita a ser guardianes de los beneficios estatales, a través de la legitimación de una definición médica de un problema, pero no necesariamente actúan como ejecutores de tratamientos. Y en el tercero sitúan las interacciones médico-paciente, en las que a través de un diagnóstico, el médico define un problema como médico y/o lo trata de alguna forma médica (Conrad y Schneider, 1980).

Con otro lenguaje, Halfmann retoma estos niveles, que se corresponden con su división en micro, meso y macro. Halfmann caracteriza a la medicalización como un proceso que se manifiesta en gradientes, algo que va en línea con lo expuesto por Conrad (2013) y Clarke et al. (2010), y desarrolla un esquema analítico donde combina los tres niveles con las dimensiones de los discursos, las prácticas y las identidades. Específicamente, desde la teoría de la biomedicalización Clarke et al. (2010) dan cuenta de la relevancia de una caracterización de los fenómenos en términos macro, meso y micro. En el escrito fundacional de esta corriente, se subraya la incidencia de las transformaciones en las tecnologías biomédicas sobre la formación o reconfiguración de biosocialidades.

También destacan el carácter complejo de la medicalización, y coinciden en identificarla como un proceso de gran magnitud, pero resaltan que no es monolítico, unidireccional ni inexorable, y que la contingencia es una de sus características más relevantes. Otro elemento que destacan es la disponibilidad y masiva accesibilidad a tecnologías biológicas, incluyendo medicamentos, instrumentos diagnósticos y otros equipamientos, así como el acceso a cuantiosa información sobre enfermedades y trastornos (nuevos, antiguos y redefinidos) contribuyen a la creación de nuevas subjetividades, identidades, y biosocialidades (Clarke et al., 2010; Bianchi, 2014a).

Rabinow trabaja el concepto de biosocialidad, con el que designa nuevas formas de grupos sociales, comunidades e identidades conformadas en torno a un cierto rasgo biológico, como puede ser una variación genética específica o una clasificación biomédica (Rabinow, 1996). La biomedicalización conduce a la transformación de los cuerpos y a la creación de nuevas identidades, ya sean individuales o colectivas, de manera que incide en las biosocialidades. En la conformación de estas identidades, la tecnociencia y las tecnologías biomédicas tienen un rol capital, porque se inscriben en múltiples aspectos de la vida diaria, e inciden en las formas en las que se vivencian las experiencias acerca de la salud y la enfermedad. Esto contribuye a la conformación de subjetividades biomedicalizadas y biosocialidades, que habilitan a su vez maneras novedosas de acceder y desenvolverse en las identidades existentes (Clarke et al., 2010; Bianchi y Rodríguez Jurado, 2018).

Por ello, y más allá del vínculo inicial de la medicalización con los estudios del control social, la desviación y la normalización social, y la impronta construccionista de los primeros análisis, las producciones académicas más recientes realizaron un giro analítico importante, valorando la pertinencia de incorporar también dimensiones económico-políticas para analizar procesos complejos que abarcan formas de saber y verdad relacionadas con el conocimiento científico-tecnológico (Conrad, 2007).

La tecnología, en particular, es entendida como uno de los motores del cambio (shifting engines) de la medicalización en el siglo XXI, que ya no opera como simple facilitadora de los procesos de medicalización, sino que constituye una fuerza impulsora de los mismos, y es parte de su proceso primario (Conrad, 2005, 2007; Moynihan y Cassels, 2005; Busfield, 2006; Cabral Barros, 2007). Esto supone el desplazamiento de los profesionales médicos como los actores más destacados para analizar la medicalización de la sociedad. Además de las tecnologías médicas, el rol destacado de la industria farmacéutica y la genética contribuyeron a posicionar a otros conceptos conexos al de medicalización, como farmacologización (Abraham, 2010; Nichter, 1996; Williams Gabe, y Davis, 2008) y genetización (Lippman, 1991; Lock, 2012), ambas nociones que expresan subcampos en los estudios de la medicalización desde el siglo XXI (Bell y Figert; 2015; Conrad, 2015).

La tecnología también incide en la creación de mercados de salud y acentúa el rol de consumidores de los usuarios del sistema de salud (Conrad y Leiter, 2004). Esto refuerza el cambio de énfasis desde 
los ámbitos profesionales médicos hacia el mercado. Para los autores, el desarrollo permanente de nuevas tecnologías, tratamientos y fármacos genera interés en los usuarios por el acceso a servicios y bienes médicos de cuño siempre renovado, y la publicidad amplifica sus demandas (Bianchi y Faraone, 2015; Bianchi, Ortega, Faraone, Gonçalves, y Zorzanelli, 2016; Bianchi, Faraone, Ortega, Gonçalves, y Zorzanelli, 2017).

Más allá de estos cambios en los actores sociales, la profesión médica sigue detentando un lugar destacado en los procesos de medicalización. Para Conrad, mantienen el rol de "guardianes de la expansión o contracción de la medicalización" (Conrad, 2013, p. 204). Y para Clarke y Shim, aunque la autonomía profesional está inobjetablemente debilitada, algunas áreas de la medicina como sector sociocultural y económico siguen siendo fuertes (Clarke y Shim, 2011).

Los estudios de género también se relacionan con los de la medicalización. Al respecto, Riska destaca que entre mediados de la década de 1970 y mediados de la década de 1980 la medicalización se posicionaba con neutralidad respecto del género. Sin embargo, los casos de estudio que abordaba mayormente se referían a varones. Entre estos ejemplos, destaca los estudios de Conrad, que abordó la entonces denominada hiperkinesis, una clasificación psiquiátrica que entonces era diagnosticada mayormente en niños varones (Riska, 2003, 2010). La inclusión de la categoría de género en los análisis de la medicalización y biomedicalización permitió dar cuenta de los modos diferenciales en los que esos procesos enlazan fármacos, enfermedades o trastornos, e identidades, y cómo estos operan en diferentes segmentos de la población, en función de alguna característica en términos de construcciones binarias de sexo femenino y masculino, o de identidades sexuales.

Así, los diagnósticos de disfunción eréctil (Fishman, 2010; Carrara, Russo y Faro, 2009; Giami, 2009); disfunción sexual femenina (Fishman, 2004), síndrome premenstrual (Greenslit, 2005), o riesgo de cáncer de mama (Fosket, 2010), entre otros, se analizan en relación a construcciones de género específicas, y motorizan procesos de medicalización y biomedicalización también particulares. Al respecto, el trabajo de Angulo, Cristófaro, Míguez, y Sánchez (2018) analizaron cómo el consumo de psicofármacos en adolescentes uruguayos responde y reproduce patrones de género, de acuerdo con los cuales se verifica una feminización del consumo de tranquilizantes, y una masculinización del consumo de estimulantes.

Con estas transformaciones, en el siglo XXI la medicalización se ha reconfigurado y se asume como un proceso crecientemente complejo, multisituado y multidireccional, que se caracteriza además por la emergencia de una biomedicina cada vez más tecnocientífica (Clarke et al., 2010; Iriart, 2018). Estas reflexiones tomaron forma en torno a la corriente de la biomedicalización que, entre otros elementos, contempla la creciente influencia de consumidores, compañías farmacéuticas y aseguradoras de salud, y la disminución del peso de los médicos y las instituciones médicas (Conrad, 2013). Aunque los aportes de Foucault estaban presentes en los debates iniciales de la perspectiva (Zorzanelli y Murilo Galvão, 2018), la biomedicalización retoma la arquitectura del pensamiento foucaultiano como referencia fundamental.

En la noción de biomedicalización convergen diferentes teorizaciones (y sus correspondientes metodologías) como biopoder y biopolítica, bioeconomía y biocapital, y la políticas de la vida misma (Clarke et al., 2010), junto con los estudios de la gubernamentalidad foucaultianos (Foucault, 2006), y el concepto de biosociabilidad (Rabinow, 1996). Y aunque también la salud, el riesgo y la vigilancia conformaban una tríada de estudio presente en los estudios de medicalización, en los fenómenos vinculados a la biomedicalización estos aspectos adquieren matices específicos. A la vez, el prefijo bio- para nominar a la teoría de la biomedicalización se relaciona con dos elementos. Por un lado marca la creciente importancia que adquiere la biología en la biomedicina actual, y por otro enlaza con los antedichos análisis del biopoder y la biopolítica foucaultianas (Clarke y Shim, 2011).

Por lo antedicho, medicalización y biomedicalización son conceptos que aluden a procesos que no se sustituyen entre sí, sino que pueden acontecer en un mismo espacio y tiempo. Las temáticas clásicas que abordó y aborda la medicalización se reformulan y son reconsideradas a la luz de procesos de biomedicalización. 
Para finalizar, el cambio de acento en los actores y la importancia de la tecnología tiene otra consecuencia vinculada con los procesos de medicalización y biomedicalización de la sociedad: la escala. La transnacionalización de la industria farmacéutica, el aumento progresivo en el uso de medicación psicoactiva como control conductual, y los adelantos en terapias y procedimientos genéticos derivan en una contundente globalización de abordajes medicalizados, y una expansión y consolidación en todo el mundo de clasificaciones diagnósticas occidentales, tanto biomédicas como biopsiquiátricas (Conrad y Bergey, 2014; Conrad, 2015).

América Latina no es ajena a este proceso, y tampoco lo es Argentina. En publicaciones académicas recientes, se destaca la relevancia de investigaciones que documenten procesos de medicalización en países no anglosajones, ya que estos últimos han sido históricamente los que más aportes empíricos han realizado a los estudios y teorías de la medicalización y biomedicalización de la sociedad.

El análisis de procesos de medicalización y biomedicalización en América Latina, entonces, contribuye a delinear contornos teórico-metodológicos específicos, y aporta para discusiones académicas, en los que nuestra región tiene mucho que ofrecer. La siguiente sección se aboca a reseñar algunas de estas contribuciones.

\section{4 ¿̨ en América Latina? Globalización de la medicalización y especificidades regionales}

De acuerdo a lo expuesto, existe una dinámica diferencial en la medicalización que surge del cruzamiento de estos procesos con otras categorías, como "edad, clase, raza, nacionalidad, sexo y más" (Rose, 2007, p. 700). De ello resulta que, para Rose, la medicalización no incide de la misma manera ni con la misma intensidad en mujeres que en hombres, en ricos que en pobres, en niños que en adultos, ni es invariable geográficamente en las diferentes regiones y países del mundo (Rose, 2007).

Sin embargo, más recientemente algunos estudios (Conrad y Bergey, 2014; Bergey, Filipe, Conrad y Singh, 2018) han presentado y compilado casos empíricos para fundamentar la inminente globalización de la medicalización, que opera como otros de los motores del cambio en los procesos en el siglo XXI. La globalización de los diagnósticos y tratamientos medicalizados es entendida como el creciente reconocimiento de parte de los actores y fuerzas sociales involucrados, de una constelación de síntomas y comportamientos en los términos de una clasificación médica o psiquiátrica, acompañado frecuentemente por el empleo de intervenciones farmacológicas (Conrad y Singh, 2018). Esta globalización, sin embargo, en modo alguno se despliega de modo uniforme en el planeta, ya que, como se ha subrayado, "no es un proceso unívoco, homogéneo o general" (Bianchi et al., 2016, p. 459).

Como señala Murillo (2018), en América Latina la medicalización entronca con toda una serie de especificidades históricas, económicas, y político-culturales, que la distinguen de cómo se han dado los procesos en otras latitudes. La medicalización en América Latina también es un tópico que ha dado lugar a numerosas investigaciones, tanto de corte teórico como de problemáticas empíricas. En particular, diagnósticos como el de TDAH (trastorno por déficit de atención e hiperactividad -APA, 2013-) ya están siendo analizados como fenómenos globales.

Configurado como un caso clásico de la medicalización desde mediados de la década de 1970, fue sistemáticamente analizado en Estados Unidos (Conrad, 1975; Conrad y Schneider, 1992; Conrad y Potter, 2003; Conrad, 2007; Conrad y Bergey, 2014; Bergey y Conrad, 2018) y es considerado un caso emblemático de expansión y migración global de diagnósticos medicalizados. Diversos trabajos sobre el TDAH en Argentina, Brasil, Chile y Uruguay han realizado los primeros aportes regionales para un análisis global de los estudios de la medicalización (Bergey et al., 2018; Bianchi et al., 2016, 2017; Faraone y Bianchi, 2018).

En 2016 se publicaron dos artículos que sistematizan y exponen resultados de estudios sociológicos dedicados a los procesos de medicalización provenientes de América Latina (Murguía, Ordorika y Lendo, 2016), y sus características epistemológicas (Murguía, Ordorika y Guerrero, 2016). Entre las conclusiones del 
relevamiento de estos autores vale reseñar algunos elementos. Entre ellos, que en la región los trabajos de corte sociológico acerca de la medicalización contactan parcialmente con múltiples otras agendas de investigación, entre las que se cuenta la de la historia de la medicina, y la salud pública. Para el caso de Argentina en particular, puede añadirse que existen otras agendas y campos de investigación que están incluyendo, entre otros abordajes, a la corriente de la medicalización. Además de las infancias y la salud mental, cuya relevancia para analizar los procesos de medicalización ha sido subrayada (Faraone y Bianchi, 2018), se incluyen tópicos clásicos como clase, economía, trabajo, legislación y derechos, y otros cuya conformación como áreas de interés investigativo es más reciente, como género, maternidad, migraciones, sexualidades, pueblos originarios, encierro punitivo, envejecimiento, alimentación, tecnologías reproductivas, etc.

Murguía y sus colegas (Murguía, Ordorika y Lendo, 2016) también señalan el marcado predominio de teorías y metodologías foucaultianas, especialmente adecuadas para las perspectivas de análisis que consideran a la medicina como estrategia biopolítica del Estado moderno, y como forma de ejercicio del control social con un doble y simultáneo carácter, a la vez represivo y persuasivo. Sin embargo, y en línea con lo que este artículo propone en la segunda parte, los autores concluyen que estos análisis se realizan, en ocasiones, sin adecuaciones que den cuenta de especificidades en los procesos regionales actuales, y/o sin un sustento empírico robusto que fundamente los resultados obtenidos.

A este análisis de los autores, sin embargo, es posible agregar que este doble carácter del control social ejercido sobre los diferentes individuos y segmentos poblacionales ni siquiera es tenido en cuenta invariablemente, y que es frecuente la orientación exclusiva hacia los elementos represivos de los procesos de medicalización, circunstancia que deriva de una de las tantas reducciones a las que se somete la complejidad de estos procesos, como se marca en la segunda parte de este artículo.

Además, marcan los autores, es necesario retener que en América Latina estas investigaciones se producen en el contexto de una salud pública con amplio predominio del modelo médico hegemónico, con la consecuente invisibilización de otras formas de entender y actuar frente a las dolencias.

Otro resultado del relevamiento es que los estudios realizados en América Latina evidencian que los procesos de medicalización son ilustrativos de las desigualdades regionales. Estas desigualdades describen un arco amplio, cuyos extremos abarcan por un lado la realidad de vastos sectores sociales con acceso limitado a servicios y medicamentos básicos, lo que restringe su derecho a la salud. Simultáneamente, y en el otro extremo, se documenta la sobreutilización de fármacos y servicios en los sectores socioeconómicamente más favorecidos. Así, los fenómenos, procesos y dinámicas medicalizadas describen una parábola cuyos extremos van de la exclusión de algunos sectores a la sobremedicalización y el hiperconsumo de medicamentos de otros. Sin embargo, lo expuesto por los autores permite asumir que en el resto de los puntos de esa parábola, se suscitan múltiples situaciones que no pueden reducirse a lecturas generalizadoras o antagónicas de las categorías.

De hecho, existen una serie de estudios en la región que se enfocan en la medicalización de la pobreza; entre ellos destaco tres que se enfocan en la infancia: el trabajo ya clásico de Scheper-Hughes (1997) sobre el consumo de leche de fórmula en bebés de sectores pobres del Alto de Brasil, y el de Barcala, Bianchi y Poverene (2017) quienes, tomando como plataforma la perspectiva de la medicalización, analizaron dos situaciones de vulnerabilidad en la niñez en la Ciudad de Buenos Aires: el padecimiento psíquico severo y la migración. Entretanto, Míguez (2010) analizó la prescripción de metilfenidato en las infancias pobres uruguayas, como modo de apaciguar sus conductas disruptivas.

Una última puntuación que Murguía y colegas (2016) entienden como auspiciosa para la perspectiva en la región, es la incipiente pero sostenida publicación de estudios de caso, muchos de ellos de corte cualitativo, ya que constituyen una contribución para comprender de un modo multidimensional al fenómeno de la medicalización.

En diálogo con estas producciones y relevamientos, en la Segunda parte de este artículo se avanza sin embargo en otra línea de contribuciones posibles, abordando algunas restricciones y limitaciones para 
investigar los fenómenos medicalizados, que se derivan de ciertas definiciones del propio concepto de medicalización que circulan en los espacios y producciones académicas de Argentina y de la región.

\section{SEgUNDA PARTE}

\section{El concepto de medicalización: su potencia y sus inexactitudes}

$\mathrm{Al}$ inicio de este artículo se planteó que el concepto de medicalización está presente transversalmente en agendas culturales, sociales, económicas y político-legislativas, a la vez que resulta ampliamente atractivo en áreas académicas, de investigación y clínico-profesionales vinculadas a la salud y la salud mental.

En este marco, es también notorio que en estos espacios las discusiones, críticas y aportes que se producen están atados a una serie de recurrentes inexactitudes, tanto en lo que se relaciona con el concepto, como con su circulación. En relación a estas inexactitudes, lo que interesa a efectos de este artículo es contribuir a la comprensión de las limitaciones y pérdida de fuerza argumental que traen estas inexactitudes para la perspectiva. Para ello se desarrollan tres líneas de exposición, que delinean límites más analíticos que empíricos.

Sintéticamente, una de ellas es la adjetivación, y consiste en suponer la noción de medicalización como un calificativo, que frecuentemente designa un atributo individual, dando pie a enunciados al estilo "tal persona está medicalizada". En esta identificación del concepto, la medicalización aparece como una propiedad que caracteriza o que le ocurre a alguien o a algunos, y se asocia fuertemente a un atributo individual. Este acontecer, además, se produce frecuentemente de modo coercitivo y externo a las intenciones o capacidad de ofrecer resistencia de quien lo experimenta. En términos de efectos metodológicos y para la investigación, esta línea es a la que más consideraciones permiten arribar.

Otra línea se destaca porque en las argumentaciones opera una reducción de los diferentes y numerosos aspectos y aristas del concepto. Entre ellas, en el artículo se trabajan dos. La primera se verifica en la homologación entre medicalización y prescripción de medicación, en tanto se toma el consumo de medicamentos como condición ineludible para la ocurrencia del fenómeno. La segunda que más frecuentemente aparece en los argumentos es que la medicalización es un asunto que concierne a los profesionales médicos, y que ellos son los principales y más significativos actores involucrados en el proceso.

Por último, otra línea que se trabaja en este artículo reside en la presunción que existen fenómenos asociados a la medicalización que son impropios o falaces como tales, y en consecuencia no deberían "verdaderamente" estar medicalizados.

En relación a estas tres líneas, el interrogante que surge es por los efectos, por las consecuencias de especie de transacción, en la que la extensión de la influencia del concepto de medicalización se intercambia por la resignación de matices y potencia analítica. Entre las consecuencias más palpables se cuentan que, como ya se mencionó, las discusiones y críticas se caracterizan por la rigidez y estereotipia. Sin embargo, la resonancia más significativa reside en que los términos en los que circula efectivamente el concepto, y los debates y discusiones que se configuran respecto de él, terminan por omitir, obturar o impedir que se planteen otros términos para el debate, con el que se podría profundizar la discusión dentro del amplio campo problemático y metodológico que habilita la perspectiva.

Con estas coordenadas, en las diferentes secciones que siguen se realiza una caracterización de cada una de las tres dificultades o inexactitudes planteadas, y se incluyen algunas puntuaciones orientadas a subrayar aquellos elementos teóricos y metodológicos de los que dispone la medicalización para salvar tales limitaciones. 


\section{La adjetivación del concepto y sus efectos individualizantes}

La propuesta general del artículo incluye ofrecer algunos elementos que permitan avanzar en la línea de una definición del concepto de medicalización que integre diversas contribuciones. Entre las contribuciones conceptuales y metodológicas ineludibles se cuentan las que realizaron tanto Conrad como Foucault. Si bien las diferencias disciplinares, metodológicas y teóricas entre ambos autores son evidentes, es posible ubicar algunos lineamientos convergentes, que coinciden en una caracterización de la medicalización como proceso heterogéneo, con multiplicidad de ángulos y que no puede abordarse en términos generales. Aunque valiosas, estas contribuciones no son recetarios para la investigación de los fenómenos medicalizados, ya que estos deben reconsiderarse y probarse en cada caso bajo estudio, tensando sus límites para una mejor comprensión de los mismos.

Uno de los aportes más sustanciales de Conrad es su elaboración de la definición de la medicalización, que hoy en día ya es canónica. De acuerdo con Conrad, la medicalización acontece "cuando un problema es definido en términos médicos, es descripto usando un lenguaje médico, es comprendido a través de la adopción de un marco médico, o es tratado con una intervención médica" (Conrad, 2007, p. 5).

Esta definición de la medicalización se asienta en una tríada de tres elementos: lo conceptual, lo procesual y lo histórico (Conrad, 2013), y no incluye un elemento que se advierte en frecuentes alusiones a la medicalización, que la asumen como un adjetivo calificativo que suele estar dotado de un carácter peyorativo.

Sostener que la medicalización no es un adjetivo requiere destacar que no es un atributo de un individuo aisladamente, ni de un conjunto de individuos como mera sumatoria, sino que es un concepto, y un concepto que ha surgido del pensamiento social. En este sentido, la medicalización es tributaria de la sociología clásica, que asume que los fenómenos sociales constituyen una entidad sui generis, que no son reductibles ni enteramente comprensibles en función de sus componentes individuales, ni de la sumatoria simple de sus elementos individuales (Durkheim, 1982). Eso posiciona a la medicalización como un proceso que no se reduce a los diferentes actores individuales que involucra y, por el contrario, expone dinámicas, lógicas y modalidades que no son comprensibles en términos de simple sumatoria.

Conrad (2013) subraya además el carácter procesual y diacrónico del término, por lo que supone, por un lado, la desmedicalización, suscitada cuando un fenómeno que se venía considerando en términos médicos ya no es merecedor de una intervención de ese tipo; y, por el otro, contempla la eventualidad de una remedicalización de problemas cuyo abordaje en términos médicos hubiese perdido peso como factor explicativo. Como resultado de esta suerte de vaivén procesual, la medicalización es un proceso en transformación.

Pero además, los fenómenos medicalizados no son idénticos a sí mismos a lo largo de la historia, por lo que una aproximación analítica diacrónica permite captar las transformaciones, devenires y características en diferentes períodos históricos. Precisamente, la clave historizante habilita una labor de desustancialización del fenómeno, de desnaturalización de la forma provisoria que adquiere en el período en el que esté siendo analizado. De hecho, la historización del concepto constituye otra de las líneas de enlace con el pensamiento de la sociología clásica.

Hasta aquí, algunos enlaces de la medicalización con ciertos aspectos de la sociología clásica. A estos puede sumarse, como un aporte del pensamiento foucaultiano, que los fenómenos medicalizados no se encuentran en armonía con el entramado de saberes, prácticas, tecnologías, instituciones, profesiones y demás elementos que involucran. Antes bien, están cruzados por agudas disputas que ponen de relieve las diferentes posturas y tensiones suscitadas en torno de sí.

Por eso, a la vez que es válida una aproximación diacrónica, es importante también asumir que en la sincronía no hay armonía, sino que en esta se expresan profundas tiranteces entre los elementos que se encuentran en relación. Por eso también, un mismo fenómeno puede, en diferentes períodos históricos, estar más o menos asociado a explicaciones medicalizadas, y puede por ello participar de 
un flujo y reflujo, al que Conrad alude como "bi-direccionalidad" (Conrad, 2013, p. 197). Con la noción de bidireccionalidad se designa esta capacidad de ciertos fenómenos y procesos, de oscilar entre la medicalización, la desmedicalización y la remedicalización a lo largo del tiempo.

Pero una vez más, esto no es todo. Como otro elemento a contemplar en el eje sincrónico del análisis, un fenómeno puede estar simultáneamente medicalizado y desmedicalizado, una posibilidad que Conrad y Foucault abordan, aunque cada uno desde diferentes andamiajes conceptuales.

Conrad habla de una dinámica de sedimentación o, literalmente, de "capa sobre capa institucional", o institutional layering (Conrad, 2013, p. 197), donde múltiples instituciones comparten el control de un problema. A esto le suma que las categorías medicalizadas son elásticas y pueden expandirse o contraerse. Sin embargo esta elasticidad no es simétrica ya que, como marca Conrad, la tendencia más advertida en los estudios empíricos es hacia la medicalización de los fenómenos, y bajo esa premisa ha estudiado cómo el TDAH es uno de los diagnósticos por excelencia que participa de esta tendencia (Conrad y Potter, 2003; Conrad y Bergey, 2014).

Para entender por qué el TDAH está en expansión como diagnóstico medicalizado es necesario remitirse a la entonces denominada "reacción hiperkinética en la infancia o adolescencia", que aparece por primera vez en Estados Unidos en la segunda edición del Manual de Diagnósticos y Estadísticas de los Trastornos Mentales, el DSM-II (APA, 1968). En la arquitectura del manual, esta nosología es ubicada en la arquitectura del manual como trastorno de conducta en la infancia y adolescencia, y fue caracterizada por "sobreactividad, inquietud y distractibilidad, y atención de corto alcance, especialmente en niños pequeños” (APA, 1968, p. 50). La elasticidad del TDAH se expresa en que surgió como categoría diagnóstica primordialmente infantil, y se mantuvo como tal en las versiones subsiguientes del manual, hasta que en el DSM-5 fue clasificado como trastorno del neurodesarrollo (APA, 2013), lo cual implica que puede ser diagnosticado y tratado en la adultez (Bianchi, 2016; Conrad, 2018).

En acuerdo con estas premisas de Conrad, y a fin de una comprensión más profunda sobre el TDAH en Argentina, vale considerar que la dimensión de lo institucional no abarca exclusivamente a los saberes que comparten dicho diagnóstico y su tratamiento, en ese "capa sobre capa institucional" del que se sirve Conrad. Hay saberes que no tienen necesariamente una expresión institucional y también están involucrados en el diagnóstico y tratamiento del TDAH (Bianchi, 2012; 2013; Bianchi et al., 2017; Faraone et al., 2018). Es frente a esta presentación del fenómeno en Argentina, y como ejemplo para pensar otras dinámicas, que resulta imperioso ampliar el análisis con otras consideraciones de Foucault.

Foucault se refirió a las implicancias de "salir de la institución" como principio metodológico. Específicamente, indicó que

lo importante (...) no son las regularidades institucionales sino (...) las disposiciones de poder, las redes, las corrientes, los relevos, los puntos de apoyo, las diferencias de potencial que caracterizan una forma de poder y que son, creo, precisamente constitutivos a la vez del individuo y de la colectividad (Foucault, 2005, p. 32).

En esta línea, planteó un descentramiento metodológico consistente en "buscar detrás de la institución para tratar de encontrar, no sólo detrás de ella sino en términos más globales, lo que podemos denominar una tecnología de poder" (Foucault, 2006, p. 141).

En Argentina, se publicaron investigaciones sobre el TDAH que registraron las voces de profesionales insertos en distintas instituciones de atención clínica, docencia e investigación. Pero además, en consonancia con esta propuesta metodológica de Foucault, también realizaron entrevistas a profesionales que, aunque no se desempeñaban en una institución determinada en ese momento, sí diagnosticaban y trataban el TDAH como característica principal de su actividad. La incorporación de estas entrevistas a las investigaciones permitió rastrear también las tecnologías de poder que operan en los saberes profesionales y que no son asimilables a una institución específica (Faraone et al., 2008; Bianchi, 2014b; Bianchi y Faraone, 2015; Bianchi et al., 2017; Faraone et al., 2018). 
Además de lo mencionado hasta aquí respecto del TDAH en Argentina, es imprescindible inscribir el institutional layering que marca Conrad en una tensión, es decir que al abordar los fenómenos medicalizados es necesario atender a que los mismos se expresan en una arena de conflicto. Este "compartir el control" entre instituciones o, más ampliamente, saberes, no se da inequívocamente en forma armónica, sino en el marco de las antedichas tensiones y disputas. ¿Y dónde aparece este estado de disputa, para el ejemplo del TDAH? Fundamentalmente en las apreciaciones mediáticas, que hablan del TDAH como un trastorno "polémico".

La condición de polémico es una de las más recurrentes caracterizaciones que se realizan respecto del TDAH en Argentina, sobre todo desde los medios de comunicación. Diferentes investigaciones (Faraone et al., 2008; Bianchi, 2012, 2014b; Faraone et al., 2018) consignaron que, en lo atinente al TDAH en Argentina, el acento está puesto reiteradamente en las polémicas, disputas, conflictos, debates y tensiones entre los profesionales de la salud, la salud mental y la educación respecto del diagnóstico y tratamiento por TDAH en niñas y niños.

Estos estudios, además, marcan la importancia de que las investigaciones que se realizan desde las ciencias sociales y humanas acerca de los fenómenos y procesos medicalizados adopten un posicionamiento metodológico propio, sin limitarse a replicar o tratar de saldar los debates que se suscitan entre los profesionales de la salud, la salud mental y la educación. Estos posicionamientos, además, realzan la necesidad de generar criterios, claves, lógicas propias de abordaje de los problemas medicalizados, que ofrezcan algo distinto de alinearse u oponerse a las posturas ya configuradas, y se alejan de una mera réplica o ventriloquía de argumentos provenientes de los saberes de la psiquiatría, la psicología o la medicina.

Frente a los abordajes que replican polémicas, entonces, resulta vital problematizar las disputas, y encontrar la regularidad en esa aparente dispersión de discursos (Foucault, 2002b). Por eso, otra herramienta teóricometodológica de Foucault que permite abordar más profundamente fenómenos y procesos medicalizados como el TDAH en Argentina es la noción de problematización.

Problematizar es renunciar a ofrecer una solución en los términos en los que se produce una polémica. Es renunciar a ponderar, evaluar y concluir cuál es la respuesta que pondría fin a las controversias que se formulan en términos de veracidad o falsedad científica (Foucault, 1991b, 2000, 2009, 2010; Dean, 1994), en este caso en torno al TDAH. Problematizar exige, por decirlo de alguna manera, un doble movimiento de apertura y recorte; es apertura porque supone ubicar la multiplicidad de respuestas posibles que surgieron para responder al problema que se plantea, en este caso los procesos de diagnóstico y tratamiento por TDAH; y es recorte porque requiere encontrar cuál es el punto en el que estas respuestas simultáneas y múltiples presentan alguna regularidad.

Es decir, problematizar desde Foucault no es solamente reconocer que algo es un problema, o que es problemático. Reconocer que algo es un problema es una exigencia en todas las investigaciones, cualquiera sea la metodología o el andamiaje teórico o epistemológico por el que se opte. Y problematizar tampoco quiere decir que porque algo es un problema, no tiene solución. Antes bien, problematizar es indagar en qué condiciones algo se configuró como problemático, y en qué circunstancias, y con la intervención de qué fuerzas, saberes, poderes, tecnologías, dispositivos, discursos y prácticas se presentan diferentes soluciones simultáneas para un mismo problema.

Por su parte, encontrar la regularidad en las diferentes posturas de los profesionales que diagnostican y tratan el TDAH en Argentina no equivale a decir que todas las posturas son iguales, sino que consiste en acentuar que lo que comparten es la alusión a un mismo elemento en términos problemáticos. Una investigación acerca del TDAH realizada en Argentina subraya que la totalidad de los profesionales entrevistados para la misma mencionaron algunos elementos como problemas: los manuales psiquiátricos, los psicofármacos prescriptos para el TDAH, y los instrumentos psicométricos que auxilian el diagnóstico (Bianchi, 2014b).

Sin embargo, que estos elementos fueran considerados problemáticos no equivalía a que todos se oponían a su uso. Para algunos profesionales era un problema que no se extendiera más la prescripción de metilfenidato, 
o que no se mejoraran los métodos de diagnóstico de los manuales para que se detectaran mejor los casos que hoy por hoy no se estarían diagnosticando, o que los instrumentos psicométricos no estuvieran mejor traducidos del idioma original para que pudieran aplicarse mejor a nuestro contexto. De manera que desde ambas perspectivas, la de Conrad y la de Foucault, el TDAH en Argentina es un ejemplo de fenómenos cuya medicalización se encuentra bajo cuestionamiento o en disputa.

\section{El concepto de medicalización y sus reduccionismos}

Otra inexactitud respecto del concepto de medicalización que circula profusamente y deriva de la anterior, es que la medicalización no es una cosa sobre la que puedan realizarse adjetivaciones, sino un modo de abordar un fenómeno, proceso o problema, una manera de volverlo inteligible. Esta inteligibilidad puede ser pensada bajo la forma de una grilla de coordenadas. Tomando la definición de medicalización propuesta por Conrad, y reproducida más arriba, las principales coordenadas pueden desagregarse como se detallan en la Figura 1.

FIGURA 1

La grilla de inteligibilidad del concepto de medicalización

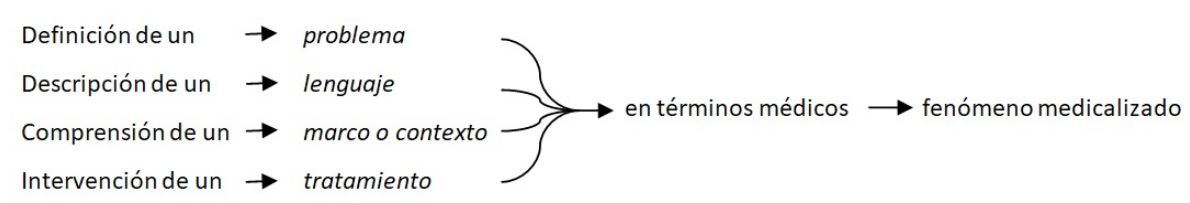

Fuente: Elaboración propia en base a Conrad (2007).

Siguiendo los términos de esta definición, entonces, puede sostenerse que un fenómeno se encuentra medicalizado si, al pasarlo por el tamiz de la grilla, se verifica la ocurrencia de alguna o todas las posibilidades de conjunción antedichas, es decir si es definido como un problema médico, si es descripto con un lenguaje médico, si es comprendido en un marco o contexto médico, y/o si es intervenido con un tratamiento médico. Estas conjunciones, a su vez, pueden ocurrir con diferentes grados de intensidad, y esa intensidad, además, debe pensarse tanto en los ejes diacrónico y sincrónico del análisis antes mencionados.

Pensar la expresión del fenómeno medicalizado en el eje diacrónico requiere inscribirlo en la historia de las explicaciones medicalizadas de las que fue depositario, en la cual las coordenadas por las que se tamizaba el fenómeno pueden haber variado en intensidad. Por otra parte, para reflexionar acerca de la intensidad del fenómeno medicalizado en el eje sincrónico, es preciso asumir que las explicaciones medicalizadas respecto de ese fenómeno coexisten en simultaneidad con otras, que no recurren a las coordenadas antedichas para aproximarse a la comprensión del mismo. Además, y más ampliamente, las propiedades mismas de la grilla pueden variar, en virtud de las transformaciones a las que está sometido el campo de los fenómenos medicalizados, por lo que, a las que detalló Conrad en su definición, pueden añadirse categorías y relaciones adicionales.

De manera que la propuesta de la grilla de inteligibilidad como aproximación al concepto de medicalización dista de constituir una lista de verificación, en la que la tarea se resuma en chequear que una propiedad de la grilla esté presente o ausente por completo en el fenómeno investigado, al modo de una categorización binaria del estilo si/no, se cumple/no se cumple la propiedad. Antes bien, se trata de asumir que las coordenadas se articulan entre sí bajo la forma de una gradación, y que esta gradación puede revestir la modalidad de un continuum, y no de un binarismo. Así, cada coordenada se puede expresar en intensidades variables. Y esa variabilidad, a la vez, puede ser pensada en términos históricos y en disputa simultánea.

En esta definición propuesta, la medicación no se presenta como elemento predominante. El fármaco puede aparecer como un tratamiento posible, pero no es excluyente, ya que pueden ocurrir procesos de medicalización que no involucran a los fármacos. Es claro, sin embargo y como Conrad reconoce, que los 
fenómenos en los que el fármaco está presente con un rol relevante, son los más en la actualidad. De hecho, la denominada corriente de la farmacologización de la sociedad es un desprendimiento de la perspectiva de la medicalización con peso propio en el siglo XXI que expresa la importancia de designar y analizar fenómenos específicos en los que el fármaco cumple un rol central (Abraham, 2010; Nichter, 1996; Williams et al., 2008) y que algunas publicaciones utilizaron para analizar el TDAH como diagnóstico medicalizado en Argentina (Faraone, Barcala, Torricelli, Bianchi, y Tamburrino, 2010; Bianchi, 2018).

De acuerdo con lo expuesto hasta aquí, la medicalización es una resultante históricamente incidida, múltiple y en tensión, de diferentes confluencias y divergencias, y no un tipo de terapéutica, la farmacológica. Por eso, las definiciones de medicalización que la asumen meramente como un sinónimo de la prescripción de medicamentos terminan por resultar reduccionistas.

A la vez, y por equivalentes motivos, la medicalización no es un asunto que competa exclusivamente a médicos. Más ampliamente, en los términos de Durkheim, la medicalización es un hecho social, y como tal compete a toda la sociedad, aunque como señaló Conrad (2013) la incumbencia de los médicos en tales procesos es variable y no excluyente. De la mano de las transformaciones reseñadas en la Parte 1 de este artículo, otros actores cumplen funciones y roles crecientemente destacados en el proceso general; entre ellos, los así denominados consumidores de salud (Conrad, 2005), considerados ya sea individualmente o en tanto grupos de apoyo o de formulación de demandas, los mercados de salud, la industria farmacéutica, la biotecnología e Internet, entre otros.

Jenkins se refirió al subsector de la salud mental vinculado a estos procesos y enumeró una serie amplia de actores, entre ellos a clínicos y asociaciones profesionales, espacios de formación académica e investigación universitaria, legislación gubernamental, cuerpos y comisiones de regulación, institutos nacionales de salud y medicina, empresas aseguradoras de salud y organizaciones médicas y de salud, establecimientos de internación y ambulatorios, residencias para adultos y de fomento de cuidados para niños y niñas, centros de detención, programas sin fines de lucro de organizaciones de participación comunitaria, grupos de apoyo y de consumidores, medios de comunicación popular y por internet, pacientes y familias, y la industria farmacéutica a través de ejecutivos de negocios, investigadores, agentes de propaganda médica, y publicidades (Jenkins, 2011, pp. 17-8).

\section{La veracidad e impropiedad del concepto de medicalización}

Finalmente, otra dificultad de las definiciones canónicas, tanto para la discusión académica como para la investigación empírica, se delinea frente al problema de la presumible propiedad o impropiedad de abordar un fenómeno cualquiera desde la perspectiva de la medicalización. También de la experiencia de participar en diferentes reuniones científicas y de discusión académica pude extraer que existe una lógica de aproximación a la noción de medicalización que se puede definir como la metáfora de la mancha, y que se opone a la propuesta de la conceptualización bajo la forma de una grilla de inteligibilidad. Aunque estas dos modalidades de definición permiten diferentes niveles de análisis y comparaciones, a los fines de este artículo restrinjo el enfoque en las limitaciones y restricciones teórico-metodológicas que conlleva la definición sustentada en la metáfora de la mancha.

En algún sentido, el mismo Conrad tributó a estas confusiones, en virtud de la definición que circuló ampliamente desde principios de la década de 1990. Esta definición difiere en algunos aspectos de la que trabajé hasta aquí, que elaboró y se difundió con posterioridad. En la definición de los años 90, Conrad afirmaba que el concepto "describe un proceso por el cual problemas no médicos se definen y tratan como problemas médicos, usualmente en términos de enfermedades y trastornos” (Conrad, 1992, p. 209). Más adelante en el mismo artículo, Conrad sostuvo que la medicalización es 
un proceso sociocultural que puede involucrar o no a la profesión médica, y conducir a un control social médico o a un tratamiento médico, o ser el resultado de la expansión intencional de la profesión médica. (...) El interés de la medicalización se ha enfocado predominantemente en problemas previamente no médicos que han sido medicalizados ( $\mathrm{y}$ frecuentemente considerados como inapropiadamente medicalizados) pero de hecho la medicalización debe incluir todos los problemas que se definen en términos médicos (Conrad, 1992, p. 211).

En esta definición está presente la idea de una mancha, que se encontraría en expansión respecto de un punto anterior y original de concentración. La dificultad que trae aparejada la metáfora de la mancha es que conlleva concebir espacios y tiempos iniciales fijos y verdaderos, que corresponderían genuinamente a la medicalización, y respecto de los cuales, y de manera impropia o falaz, el proceso se ha ensanchado. La idea de una mancha también trae consigo una suerte de regla de validación, que establece condiciones para diferenciar entre los fenómenos que deberían y no deberían tratarse desde la medicalización. Con posterioridad, Conrad complejizó esta definición, tal como se trabaja en el apartado 7 de este artículo. Sin embargo, la metáfora de la mancha es muy pregnante en la actualidad. Una manera de ir más allá de estas restricciones es incorporar al análisis algunas consideraciones de Foucault.

Uno de los aportes de Foucault al concepto de medicalización deriva de cómo entiende el campo de acción de la medicina. Según él, no se trata de un campo único e inalterable, sino que

cada cultura define de una forma propia y particular el ámbito de los sufrimientos, de las anomalías, de las desviaciones, de las perturbaciones funcionales, de los trastornos de la conducta que corresponden a la medicina, suscitan su intervención y le exigen una práctica específicamente adaptada (...). En último término la enfermedad es, en una época determinada y en una sociedad concreta, aquello que se encuentra práctica o teóricamente medicalizado(Foucault, 1996, p. 21).

Los lineamientos presentes en este fragmento están en consonancia con la importancia de abordar a la medicalización desde coordenadas historizantes, desnaturalizantes, desustancializadoras, desprovistas de presupuestos, y que entiendan a la verdad en tanto resultante parcial e inscripta en una disputa sostenida en un interjuego mayor en el que intervienen múltiples actores (Bianchi, 2010). Además, estas consideraciones derivan en que no existen fenómenos intrínsecamente medicalizados; no lo están en la actualidad, ni lo están en términos históricos. Antes bien, y retomando la propuesta de la grilla de inteligibilidad, se puede pensar que un fenómeno o un problema están medicalizados si, al pasarlo por las coordenadas de la grilla, quedan adheridos ciertos sentidos y propiedades en la trama, que nos resultan inteligibles para la investigación.

Sin embargo, y como la trama no es homogénea sino dispar y en transformación, el análisis centrado en el grillado y no en la idea de mancha en expansión hace posible captar las modificaciones y vaivenes en los contornos de la medicina, y más ampliamente de la salud, la enfermedad, la normalidad y la vida, de manera que pueden tamizarse fenómenos y problemas nuevos, o fenómenos y problemas que se han configurado de un modo específico en la historia.

Esta forma de aproximarse a los fenómenos se inscribe a la vez en el enfoque foucaultiano de los regímenes de veridicción (Foucault, 1991a, 2004, 2009) con el que alude al conjunto de reglas que conforman los criterios de verdad en una sociedad y en relación a cierto discurso. Estos criterios permiten decidir acerca de la veracidad o falsedad de ciertos enunciados y formulaciones.

Este tipo de análisis conlleva un abordaje histórico que no se centra en realizar "una historia del error, ligada a una historia de las prohibiciones"(Foucault, 2004, p. 53), ni tampoco en develar el error oculto en una aparente verdad racional o científica.

En cambio, el interés reside en conocer en qué condiciones y con qué efectos se ejerce una veridicción, y qué condiciones se producen para que ciertos enunciados se pronuncien en relación la consideración de que un fenómeno o problema dado está verdaderamente medicalizado. Tales enunciados serán considerados verdaderos o falsos, de acuerdo a las reglas de los diversos discursos, saberes y sentidos sociales que lo toman como objeto. El caso del TDAH en Argentina, como fue expuesto hasta aquí, es uno de los ejemplos más emblemáticos que ilustran el carácter no armónico sino en disputa de esos diferentes criterios de verdad que pugnan por hacer primar sus reglas en la multiplicidad de saberes y sentidos que se pronuncian en torno al 
TDAH. Estos enunciados, además, provienen sólo parcialmente de ámbitos médicos y clínicos, porque la medicalización, como se señaló, no es un asunto de médicos exclusiva ni mayoritariamente.

En términos más amplios, entonces, los fenómenos y problemas medicalizados, y las disputas por establecer su veracidad, son especialmente expresivos de los modos de entender la verdad cuando esta adquiere la forma del discurso científico y de las instituciones que la producen. Adicionalmente, la perspectiva de Foucault liga la verdad a los sistemas de poder que la producen, incitan y mantienen (Foucault, 1991a), y eso permite interrogarse también por las condiciones que hacen posible tomar por verdaderos, o no, a ciertos enunciados respecto de la medicalización, y por los efectos de poder que esos saberes y esas verdades pueden provocar.

Un último elemento de la batería teórico-metodológica foucaultiana que es útil para aproximarse a los fenómenos, procesos, problemas y dinámicas medicalizadas es la noción de formación discursiva. La formación discursiva se caracteriza por designar a un conjunto de enunciados que se articula con prácticas concretas. Esta articulación, empero y al igual que los problemas medicalizados, no constituyen un entramado homogéneo. Antes bien, se caracterizan por la dispersión, es decir que su procedencia remite a diversos ámbitos (Foucault, 2002b; Murillo, 1996; Bianchi, 2015). En los procesos de medicalización, esta dispersión se expresa en que la procedencia de los enunciados no se reduce al campo de la salud, sino que estos incluyen otros campos, como el pedagógico-educativo, el familiar, el farmacéutico, el legislativo, el tecnológico, entre muchos otros.

Otra característica de la formación discursiva es que no tematiza un objeto, sino que es constituyente del objeto. Por tal motivo, no posee una esencia de antemano, inmutable y atemporal, sino que se inscribe en un proceso de transformación de los sentidos que la configuran en el tiempo. Tanto la emergencia de una formación discursiva como su transformación, además, tienen un insoslayable componente estratégico que se pone en juego también en las dinámicas medicalizadas.

En resumen, la formación discursiva se cimenta en una serie de postulados: articulación en la dispersión, multiplicidad de campos de procedencia, emergencia y circulación estratégica, y constitución del objeto. Estos ejes resultan útiles para reflexionar acerca de los problemas medicalizados, ya que la conformación, puesta en circulación, y efectos que producen la medicalización de un fenómeno no son privativos de los discursos de la medicina, ni siquiera de la salud. Los actores y fuerzas sociales que intervienen en la medicalización en el siglo XXI exigen disponer de herramientas metodológicas que capten especificidades que contribuyan al análisis de las relaciones de fuerza que se ponen en juego en el campo estratégico que queda conformado en torno a tales procesos y fenómenos.

\section{Palabras finales}

En el artículo analicé una serie de aspectos teórico-metodológicos que pueden enriquecer el abordaje de los fenómenos medicalizados. Las características de estos fenómenos, sin embargo, también inciden en el tipo de conclusiones a las que es posible arribar cuando se realizan investigaciones en esta clave.

Un primer elemento a tener en cuenta es el carácter complejo, en curso y en tensión de los fenómenos medicalizados. Este panorama deriva en el renunciamiento a realizar inferencias generales, a la vez que exige realizar análisis que permitan una profundización dentro de las diferentes aristas de la problemática.

La referencia a su carácter de complejos no se agota en que se trata de procesos que incluyen una multiplicidad de actores y fuerzas sociales, sino que se continúan en que estos contienen e impulsan lógicas no unitarias ni convergentes, que pueden ser consonantes o contrapuestas, y que pueden funcionar y reproducirse aún en la contradicción. El carácter complejo también se manifiesta en que los procesos de medicalización abarcan múltiples estrategias, y estas no son generales sino parciales, fragmentadas, no siempre orientadas en un sentido afín, y en ocasiones decididamente divergentes. Esta misma complejidad se amplía a múltiples instituciones, tecnologías, saberes, prácticas, dispositivos y profesiones, entre otros tantos 
elementos. En este sentido, el estudio de Rodríguez Zoya (2017) sobre la complejidad del campo de la salud y la comunicación es una referencia para expandir y complementar las consideraciones vertidas en este artículo.

Además de la complejidad, otra característica de los procesos de medicalización es que el conjunto anteriormente enunciado no es armónico, sino que se producen tensiones, cruces, luchas, conflictos, debates y disputas de diverso calibre. Es decir que en la antedicha complejidad no hay calma, quietud, ni consenso, sino tensiones. Algunas relaciones entre actores y fuerzas en el campo fenoménico pueden ser marcadamente contradictorias y antagónicas. Pero simultáneamente, en otras líneas de fuerza dentro del mismo campo problemático se puede producir un accionar diferente, de tipo intersticial, con lógicas de funcionamiento en los resquicios, que traen su propia dinámica al proceso y coexisten con él en tensión. Las estrategias de marketing farmacéutico en salud mental infantil en Argentina son ejemplo de mixtura entre ambas dinámicas (Bianchi y Faraone, 2015; Bianchi et al., 2016).

Por último, sostengo que se trata de fenómenos en curso, porque esa tensión no está saldada, agotada ni cancelada; los conflictos que se suscitan todavía están desplegándose, moviéndose o desarrollándose, y ni el devenir ni el final de estas luchas complejas pueden avizorarse del todo con los elementos de análisis con los que se cuenta en este momento.

La medicalización, entonces, admite muchos ángulos de aproximación, congrega muchos actores sociales y en cada región adquiere características particulares. Con este panorama, resulta poco conducente y muy poco riguroso pretender que las investigaciones realizadas en una zona geográfica o en relación a un período de tiempo puedan ofrecer explicaciones omniabarcativas y directamente extrapolables a otras coordenadas fenoménicas.

Un corolario de lo mencionado es que, dado que los procesos de medicalización se encuentran en curso y transformación permanente, en ocasiones las investigaciones recurren a mapeos de situación. Lejos de considerar estos mapeos como restricciones de análisis más profundos, entiendo que estos constituyen insumos relevantes en línea con la idea de disponer de elementos empíricos que permitan discutir y tensar la teoría, para poner a la medicalización "contra las cuerdas" y no permanecer en una situación inercial o de confort investigativo.

Habida cuenta de lo expuesto, la propuesta de Rose (2012) de realizar cartografías del presente ofrece un encuadre posible para avanzar, dado que en la actualidad, y en el marco de lo que él entiende como la vigencia de las políticas de la vida, se han producido una serie de mutaciones que abren a la posibilidad de múltiples futuros. Las historias del presente, las genealogías que resultaron útiles para analizar la política de la salud en el siglo XX, para Rose ya no son adecuadas para dar cuenta de las políticas de la vida en este siglo. El objetivo de estas genealogías y estas historias del presente (cuyos lineamientos provienen de Foucault) fue abrir el presente a una reformulación, pensando las contingencias, rastreando la heterogeneidad que condujo a la aparente unidad del presente, historizando aspectos presumiblemente ahistóricos y resaltando el rol del conocimiento.

Según Rose, frente a la actual situación, en la que el presente es un constante fluir, estas propuestas ven diluida su anterior radicalidad. La tumultuosa coyuntura conjuga un pasado cuya seguridad se desvanece y un futuro de inseguridades apenas imaginables. De allí que la realización de cartografías, propuesta que Rose entiende como más modesta, apunta a desestabilizar el futuro, reconociendo su apertura y multiplicidad. Si no hay un solo futuro posible, intervenir en el presente múltiple y contingente puede tener resonancias en aspectos de esos futuros.

Aunque estoy muy lejos de pensar que las genealogías y las historias del presente hayan agotado su potencialidad analítica, es inobjetable la consideración de Rose acerca de que las cartografías permiten una aproximación más que adecuada para encarar los fenómenos cuya medicalización es parte de una disputa permanente. 


\section{BiBliografía}

Abraham, J. (2010). Pharmaceuticalization of society in context: Theoretical, Empirical and Health Dimensions. Sociology, 44(4), 603-622. doi:10.1177/0038038510369368.

American Psychiatric Association, APA. (1968). Diagnostic and Statistical Manual of Mental Disorders (Second Edition). Washington: American Psychiatric Association.

American Psychiatric Association, APA. (2013). Diagnostic and Statistical Manual of Mental Disorders (Fifth Edition). Washington: American Psychiatric Association.

Angulo, S., Cristófaro, A., Míguez, M. N., y Sánchez, L. (2018). Inmediatez y conflicto. Medicación con psicofármacos en las infancias y adolescencias en Uruguay. En Faraone, S. y Bianchi, E. (Comps.), Medicalización, Salud Mental e Infancias. Perspectivas y debates desde las Ciencias Sociales en Argentina y el sur de América Latina (pp. 401-424). Buenos Aires: Teseo.

Barcala, A., Bianchi, E. y Poverene, L. (2017). Medicalización de la infancia: sus efectos en la salud mental. Derecho de Familia. Revista Interdisciplinaria de Doctrina y Jurisprudencia, 82, 99-113.

Becker, H. (2009), Outsiders: hacia una sociología de la desviación. Buenos Aires: Siglo XXI.

Bell, S. y Figert, A. (2015). Reimagining (bio)medicalization, pharmaceuticals and genetics. Old critiques and new engagements. New York-London: Routledge.

Bergey, M. y Conrad, P. (2018). The Rise and Transformation of ADHD in the United States. En Bergey, M., Filipe, A., Conrad, P. y Singh, I. (Eds.), Global Perspectives on ADHD: Social Dimensions of Diagnosis and Treatment in 16 Countries. (pp. 9-33). Baltimore: Johns Hopkins University Press.

Bergey, M., Filipe, A., Conrad, P. y Singh, I. (2018). Global Perspectives on ADHD: Social Dimensions of Diagnosis and Treatment in 16 Countries. Baltimore: Johns Hopkins University Press.

Bianchi, E. (2010). La perspectiva teórico-metodológica de Foucault. Algunas notas para investigar al ADHD. Revista Latinoamericana de Niñez y Juventud, 8, 43-65.

Bianchi, E. (2012). ADHD y discursos de la salud sobre la infancia en el AMBA (1994-2011). Configuraciones discursivas y efectos de poder (Tesis de maestría inédita). Universidad de Buenos Aires, Buenos Aires.

Bianchi, E. (2014a). Biopolítica: Foucault y después. Contrapuntos entre algunos aportes, límites y perspectivas asociados a la biopolítica contemporánea. Astrolabio, 1(13), 218-251.

Bianchi, E. (2014b). Gubernamentalidad, tecnologias y disputas. Una genealogía de los saberes profesionales acerca del ADHD (Trastorno por Déficit de Atención con Hiperactividad) en la infancia (1994-2012) (Tesis de Doctorado inédita). Universidad de Buenos Aires, Buenos Aires.

Bianchi, E. (2015). Infancia, normalización y salud mental. Figuras históricas y encadenamientos actuales en la formulación del ADHD. História, Ciências, Saúde, 3(22), 761-779. doi: 10.1590/S0104-59702015000300006.

Bianchi, E. (2016). Diagnósticos psiquiátricos infantiles, biomedicalización y DSM: ¿hacia una nueva (a)normalidad? Revista Latinoamericana de Ciencias Sociales, Niñez y Juventud, 1(14), 417-430. doi: 10.11600/1692715x.14128210715.

Bianchi, E. (2018). Saberes, fármacos y diagnósticos. Un panorama sobre producciones recientes en torno a la farmacologización de la sociedad. Psicología, Conocimiento y Sociedad, 8(2) 214-257. doi: 10.26864/ PCS.v8.n2.11.

Bianchi, E. y Faraone, S. (2015). El Trastorno por Déficit de Atención e Hiperactividad (TDA/H). Tecnologías, actores sociales e industria farmacéutica. Physis, 25(1), 75-98. doi: 10.1590/S0103-73312015000100006.

Bianchi, E. y Rodríguez Jurado, S. (2018). Biomedicalización de los tiempos. Terapéuticas, biosocialidades y cuidados cotidianos en familias de niños y niñas con diagnóstico de TEA en Buenos Aires. Saúde e Sociedade. En prensa.

Bianchi, E., Faraone, S., Ortega, F., Gonçalves, V. P. y Zorzanelli, R. T. (2017). Controversias acerca del diagnóstico de TDAH y la prescripción de metilfenidato en los debates sobre la medicalización en Argentina y Brasil. Physis, 27(3), 641-660. doi: 1590/S0103-73312017000300014. 
Bianchi, E., Ortega, F., Faraone, S., Gonçalves, V. P. y Zorzanelli, R. T. (2016). Medicalización más allá de los médicos. Marketing farmacéutico en torno al Trastorno por Déficit de Atención e Hiperactividad en Argentina y Brasil (1998-2014). Saúde e Sociedade, 25(2), 452-462. doi: 10.1590/S0104-1290201615398.

Busfield, J. (2006). Pills, Power, People: Sociologicals Understandings of the Pharmaceutical Industry. Sociology, 40(2), 297-314. doi: 10.1177/0038038506062034.

Busfield, J. (2017). The concept of medicalisation reassessed. Sociology of Health \& Illness,39(5), 759-774. doi: $10.1111 / 1467-9566.12538$.

Cabral Barros, J. A. (2007). Nuevas tendencias de la medicalización.Ciência \& Saúde Coletiva, 13, 579-587. doi: 10.1590/S1413-81232008000700007.

Carrara, S., Russo, J. A. y Faro, L. (2009). A política de atenção à saúde do homem no Brasil: os paradoxos da medicalização do corpo masculino. Physis, 19(3), 659-678. doi: 10.1590/S0103-73312009000300006.

Clarke, A. y Shim, J. (2011). Medicalization and Biomedicalization Revisited: Technoscience and Transformations of Health, Illness and American Medicine. En Pescosolido, B. et al. (Eds.), Handbook of the Sociology of Health, Illness, and Healing. A Blueprint for the 21st Century (pp. 173-195). New York: Springer.

Clarke, A., Mamo, L., Fosket, J., Fishman, J. y Shim, J. (2010). Biomedicalization. Technoscience, Health and Illness. Durham-London: Duke University.

Conrad, P. (1975). The discovery of hyperkinesis. Notes on the medicalization of deviant behavior. Social Problems, 23(1), 12-21.

Conrad, P. (1979) Types of medical social control. Sociology of Health and Illness. 1(1), 1-11.

Conrad, P. (1992). Medicalization and Social Control. Annual Review of Sociology, 18, 209-232.

Conrad, P. (2005). The shifting engines of medicalization. Journal of Health and Social Behavior, 46, 3-14.

Conrad, P. (2007). The Medicalization of Society: On the Transformation of Human Conditions into Treatable Disorders. Baltimore: Johns Hopkins University Press.

Conrad, P. (2013). Medicalization: Changing contours, characteristics, and contexts. En Cockerham, W. (Ed.), Medical Sociology on the Move: New Directions in Theory (pp.195-214). New York: Springer.

Conrad, P. (2015). Foreword. En Bell, S. y Figert, A. (Eds.), Reimagining (bio)medicalization, pharmaceuticals and genetics. Old critiques and new engagements (pp. vii-ix). New York-London: Routledge.

Conrad, P. (2018). Prefacio. En Faraone, S. y Bianchi, E. (Comps.), Medicalización, salud mental e infancias: Perspectivasy debates desde las Ciencias Sociales en Argentina y el sur de América Latina (pp. 11-14). Buenos Aires: Teseo.

Conrad, P. y Bergey, M. (2014). The impending globalization of ADHD: Notes on the expansion and growth of a medicalized disorder. Social Science and Medicine, 122, 31-43. doi: 10.1016/j.socscimed.2014.10.019.

Conrad, P. y Leiter, V. (2004). Medicalization, markets and consumers. Journal of Health and Social Behavior, 45, 158-176.

Conrad, P. y Potter, D. (2003). From Hyperactive Children to ADHD Adults. Observations on the Expansion of Medical Categories. En Conrad, P. y Leiter, V. (Eds.), Health and Health Care as Social Problems (pp. 39-65). United Kingdom: Rowman \& Littlefield.

Conrad, P. y Schneider, J. (1980). Looking at levels of medicalization: a comment on Strong's critique of the thesis of medical imperialism. Social Science and Medicine, 14(1), 75-79.

Conrad, P. y Singh, I. (2018). Reflections on ADHD in a Global Context. En Bergey, M., Filipe, A., Conrad, P. y Singh, I. (Eds.), Global Perspectives on ADHD: Social Dimensions of Diagnosis and Treatment in 16 Countries (pp. 376-390). Baltimore: Johns Hopkins University Press.

Conrad, P. y Schneider, J. W. (1992). Deviance and Medicalization. From Badness to Sickness. Philadelphia: Temple University.

Davis, J. E. (2009). Medicalization, Social Control, and the Relief of Suffering. En Cockerham, W. (Ed.), The New Blackwell Companion to Medical Sociology (pp. 211-241). Oxford: Wiley-Blackwell. 
Dean, M. (1994). Critical and Effective Histories. Foucault's Methods and Historical Sociology. London and New York: Routledge.

Durkheim, É. (1982). Las reglas del método sociológico. España: Hyspamérica.

Faraone, S. y Bianchi, E. (2018). Medicalización, salud mental e infancias: Perspectivas y debates desde las Ciencias Sociales en Argentina y el sur de América Latina. Buenos Aires: Teseo.

Faraone, S., Barcala, A., Torricelli, F., Bianchi, E., Ballesteros, I., Tamburrino, M. C., López Casariego, V. y Leone, C. (2008). Campo salud. En Arizaga, C. y Faraone, S. (Dir.), La medicalización de la infancia. Niños, escuela y psicotrópicos. SEDRONAR-II.GG. Recuperado de: http://www.observatorio.gov.ar/investigaciones/info\%20f inal\%20Dic\%202008_medicalizacion\%20en\%20la\%20infancia.pdf [consulta, diciembre de 2017]

Faraone, S., Barcala, A., Torricelli, F., Bianchi, E. y Tamburrino, M. C. (2010). Discurso médico y estrategias de marketing de la industria farmacéutica en los procesos de medicalización de la infancia en Argentina. InterfaceComunicação, Saúde, Educação, 14(34), 485-495.

Faraone, S., Bianchi, E., Leone, C., Torricelli, F., Oberti, M., y Valero, A. S. (2018). Actores sociales en torno al TDAH en las infancias. Una década de investigaciones en Argentina. En Faraone, S. y Bianchi, E. (Comps.), Medicalización, salud mental e infancias: Perspectivas y debates desde las Ciencias Sociales en Argentina y el sur de América Latina (pp. 267-304). Buenos Aires: Teseo.

Fishman, J. (2004). Manufacturing desire: the commodification of female sexual dysfunction. Social Studies of Science, 34(2), 187-218. doi: 10.1177/0306312704043028.

Fishman, J. (2010). The Making of Viagra. The Biomedicalization of Sexual Dysfunction. En Clarke, A., Mamo, L., Fosket, J., Fishman, J. y Shim, J. (Eds.), Biomedicalization. Technoscience, health and illness (pp. 289-306). Durham-London: Duke University.

Fosket, J. (2010). Breast Cancer Risk as Disease. Biomedicalizing Risk. En Clarke, A., Mamo, L., Fosket, J., Fishman, J. y Shim, J. (Eds.), Biomedicalization. Technoscience, health and illness (pp. 331-352). Durham-London: Duke University.

Foucault, M. (1991a). Microfísica del poder. Madrid: La Piqueta.

Foucault, M. (1991b). Saber y verdad. Madrid: La Piqueta.

Foucault, M. (1996). La vida de los hombres infames. Buenos Aires: Altamira.

Foucault, M. (2000). Defender la sociedad. Buenos Aires: FCE.

Foucault, M. (2002a). Historia de la sexualidad. Argentina: Siglo XXI.

Foucault, M. (2002b). La arqueología del saber. Buenos Aires: Siglo XXI.

Foucault, M. (2004). Nacimiento de la biopolítica. Buenos Aires: FCE.

Foucault, M. (2005). El poder psiquiátrico. Argentina: FCE.

Foucault, M. (2006). Seguridad, territorio, población. Argentina: FCE.

Foucault, M. (2009) El gobierno de síy de los otros. Argentina: FCE.

Foucault, M. (2010). Polémicas, problemas y problematizaciones. En Foucault, M., Obras Esenciales. Estética, ética y hermenéutica (pp. 991-998). Barcelona: Paidós.

Freidson, E. (1978). La profesión médica. Barcelona: Península.

Giami, A. (2009). Da impotência à disfunção erétil. Destinos da medicalização da sexualidade. Physis, 19(3), 637-658. doi: 10.1590/S0103-73312009000300005.

Goffman, E. (1998a). Estigma. La identidad deteriorada. Argentina: Amorrortu.

Goffman, E. (1998b). Internados. Ensayos sobre la situación social de los enfermos mentales. Argentina: Amorrortu.

Greenslit, N. (2005). Depression and consumption: psychopharmaceuticals, branding, and new identity practices. Culture Medicine and Psychiatry, 29(4), 477-502. doi: 10.1007/s11013-006-9005-3.

Halfmann, D. (2011). Recognizing medicalization and demedicalization: Discourses, practices, and identities. Health, 16(2), 1-22. doi: 10.1177/1363459311403947. 
Huertas, R. (2008). Los laboratorios de la norma. Medicina y regulación social en el Estado liberal. España: OctaedroConsejo Superior de Investigaciones Científicas.

Huertas, R. (2009). Medicina social, control social y políticas del cuerpo. La subjetivación de la norma. En Miranda, M. y Girón Sierra, A. (Coords.), Cuerpo, Biopolitica y Control Social (pp. 19-42). Buenos Aires: Siglo XXI.

Illich, I. (1976). Némesis médica. La expropiación de la salud. México: J. Mortiz.

Iriart, C. (2018). Medicalización, biomedicalización y proceso de salud-padecimiento-atención. En Faraone, S. y Bianchi, E. (Comps.), Medicalización, Salud Mental e Infancias. Perspectivas y debates desde las Ciencias Sociales en Argentina y el sur de América Latina (pp. 93-110). Buenos Aires: Teseo.

Jenkins, J. (2011). Psychopharmaceutical Self and Imaginary in the social field of Phychiatric Treatment. En Jenkins, J. (Ed.), Pharmaceutical Self. The Global Shaping of Experience in an Age of Phychopharacology (pp. 17-40). Santa Fe: SAR.

Lippman, A. (1991). Prenatal genetic testing and screening: Constructing needs and reinforcing inequities. American Journal of Law \& Medicine, 17(1-2), 15-50.

Lock, M. (2012). From genetic to postgenomics and the discovery of the new social body. En Inhorn, M. y Wentzell, E. (Eds.), Medical anthropology in the intersections (pp.129-160). Durham: Duke University Press.

Lupton, D. (1997). Foucault and the medicalization critique. En Petersen, A. y Bunton, R. (Eds.), Foucault, Health and Medicine (pp. 94-110). London-New York: Routledge.

Míguez, M. N. (2010). La sujeción de los cuerpos dóciles. Medicación abusiva con psicofármacos en la niñez uruguaya (Tesis Doctoral). Universidad de Buenos Aires. Recuperada de: http://estudiosociologicos.org/portal/sujecion -cuerpos-dociles/

Moynihan, R. y Cassels, A. (2005). Medicamentos que nos enferman e industrias farmacéuticas que nos convierten en pacientes. Barcelona: Terapias Verdes.

Murguía, A., Ordorika, T. y Lendo, L. (2016). El estudio de los procesos de medicalización en América Latina. História, Ciências, Saúde, 23(3), 635-651. doi: 10.1590/S0104-59702016005000009.

Murguía, A., Ordorika, T. y Guerrero, F. (2016). Consideraciones epistemológicas en torno a la medicalización en América Latina: balances y propuestas. Ludus Vitalis,, XXIV(46), 99-128.

Murillo, S. (1996). El discurso de Foucault. Estado, locura y anormalidad en la construcción del individuo moderno. Buenos Aires: CBC.

Murillo, S. (2018). El gobierno de las infancias. En Faraone, S. y Bianchi, E. (Comps.), Medicalización, Salud Mental e Infancias. Perspectivas y debates desde las Ciencias Sociales en Argentina y el sur de América Latina (pp. 27-60). Buenos Aires: Teseo.

Nichter, M. (1996). Pharmaceuticals, the Commodification of Health, and the Health Care-Medicine use Transition. En Nichter, M. y Nichter, M. (Eds.), Anthropology and international health: Asian Care Studies, Theory and Practice in Medical Anthropology and International Health (pp. 265-326), Amsterdam: Gordon \& Breach Science Publishers.

Parsons, T. (1999). El sistema social. Madrid: Alianza.

Pitts, J. (1968). Social control: the concept. En Sills, D. (Ed.), International encyclopedia of social sciences (pp. 381396). New York: Macmillan.

Rabinow, P. (1996). Essays on the Anthropology of Reason. New Jersey: Princeton University.

Riska, E. (2003). Gendering the medicalization thesis. Gender Perspectives on Health and Medicine: Key Themes Advances in Gender Research, 7, 59-87.

Riska, E. (2010). Gender and medicalization and biomedicalization theories. En Clarke, A., Mamo, L., Fosket, J., Fishman, J. y Shim, J. (Eds.), Biomedicalization. Technoscience, health and illness (pp. 147-172). DurhamLondon: Duke University.

Rodríguez Zoya, P. G. (2017). Notas para pensar la complejidad del campo de la comunicación y salud. En Petracci, M., Schwarz, P. K. N. y Rodríguez Zoya, P. G., Comunicación y salud. Las relaciones entre médicos y pacientes en la Modernidad Tardia (pp. 13-68). Buenos Aires: Teseo. 
Rose, N. (2007). Beyond Medicalization. The Lancet, 369(9562), (pp. 700-2). doi: 10.1016/S0140-6736(07)60319-5 Rose, N. (2012). Politicas de la vida: biomedicina, poder y subjetividad en el siglo XXI. La Plata: UNIPE.

Scheper-Hughes, N. (1997). La muerte sin llanto. Violencia y vida cotidiana en Brasil. Barcelona: Ed. Ariel.

Sismondo, S. (2010). An Introduction to Science and Technology Studies. Sussex: Wiley- Blackwell.

Szasz, T. (1973). El mito de la enfermedad mental. Buenos Aires: Amorrortu.

Szasz, T. (2001). Ideologia y enfermedad mental. Buenos Aires: Amorrortu.

Williams, S, Gabe, J. y Davis, P. (2008). The sociology of pharmaceuticals: progress and prospects. Sociology of Health \& Illness, 30(6), (pp. 813-824). doi: 10.1111/j.1467-9566.2008.01123.x.

Zola, I. (1972). Medicine as an institution of social control. The sociological Review, 20, 487-504.

Zorzanelli, R. T. y Murilo Galvão, A. C. (2018). O conceito de medicalização em Michel Foucault na década de 1970. Interface, 22(66), (pp. 721-731). doi: 10.1590/1807-57622017.0194. 